OPEN ACCESS

Edited by:

Norberto Garcia-Cairasco, University of São Paulo, Brazil

Reviewed by:

Yam Nath Paudel, Monash University Malaysia, Malaysia Emilio Russo,

University of Catanzaro, Italy

*Correspondence:

Hua-Jun Feng feng.huajun@mgh.harvard.edu

Specialty section:

This article was submitted to

Epilepsy,

a section of the journal

Frontiers in Neurology

Received: 20 August 2021 Accepted: 13 October 2021 Published: 04 November 2021

Citation:

Guo J, Min D and Feng H-J (2021) Genistein, a Natural Isoflavone, Alleviates Seizure-Induced Respiratory Arrest in DBA/1 Mice.

Front. Neurol. 12:761912.

doi: 10.3389/fneur.2021.761912

\section{Genistein, a Natural Isoflavone, Alleviates Seizure-Induced Respiratory Arrest in DBA/1 Mice}

\author{
Jialing Guo ${ }^{1,2,3}$, Daniel Min ${ }^{2}$ and Hua-Jun Feng ${ }^{2,3 *}$ \\ ${ }^{1}$ Department of Neurology, Xiangya Hospital, Central South University, Changsha, China, ${ }^{2}$ Department of Anesthesia, Critical \\ Care and Pain Medicine, Massachusetts General Hospital, Boston, MA, United States, ${ }^{3}$ Department of Anesthesia, Harvard \\ Medical School, Boston, MA, United States
}

Objective: Sudden unexpected death in epilepsy (SUDEP) is a fatal event that ranks second in years of potential life lost among neurological disorders. Seizure-induced respiratory arrest (S-IRA) is the primary instigator leading to death in many SUDEP cases. However, there are currently no effective preventive strategies against S-IRA other than the seizure control. Therefore, it is critical to develop new avenues to prevent SUDEP by investigating the pharmacological interventions of S-IRA. In the present study, we examined the effect of genistein, an isoflavone found in various dietary vegetables, on the incidence of S-IRA in DBA/1 mice.

Methods: DBA/1 mice exhibited generalized seizures and S-IRA when subjected to acoustic stimulation. Genistein was intraperitoneally administered alone or in combination with an adrenoceptor antagonist and a serotonin (5-HT) receptor antagonist, respectively. The effects of drug treatments on S-IRA incidence and seizure behaviors were examined.

Results: The incidence of S-IRA in DBA 1 mice was significantly reduced $2 \mathrm{~h}$ after injection of genistein at $1-90 \mathrm{mg} / \mathrm{kg}$ as compared with that in the vehicle control. Genistein could block S-IRA without interfering with any component of seizures, especially at relatively lower dosages. The S-IRA-suppressing effect of genistein was reversed by an $\alpha 2$ adrenoceptor antagonist but was not altered by an $\alpha 1$ antagonist. The inhibitory effect of genistein on S-IRA was not affected by a 5- $\mathrm{HT}_{3}$ or $5-\mathrm{HT}_{2 \mathrm{~A}}$ receptor antagonist.

Significance: Our data show that genistein reduces S-IRA incidence and can specifically block S-IRA in DBA/1 mice. Its suppressing effect on S-IRA is dependent on activating $\alpha 2$ adrenoceptors. Our study suggests that genistein, a dietary supplement, is potentially useful to prevent SUDEP in at-risk patients.

Keywords: SUDEP, S-IRA, dietary supplement, norepinephrine, serotonin, therapeutics

\section{INTRODUCTION}

Sudden unexpected death in epilepsy (SUDEP) ranks second in years of potential life lost among common neurological disorders (1). The lifetime risk of SUDEP is estimated up to $8 \%$ in epilepsy patients, and the risk of sudden death is 24 - to 28 -fold higher in young people with epilepsy than that in the general population $(1,2)$. Patients with refractory epilepsy are especially vulnerable to 
SUDEP, with a rate of up to 9 per 1,000 patient-years (3). Multiple pathophysiological mechanisms have been proposed for SUDEP (4-9). However, both clinical and animal studies demonstrated that seizure-induced respiratory arrest (S-IRA) is the major cause of death in SUDEP (10-20). There are currently no effective preventive strategies against S-IRA other than the control of generalized tonic-clonic seizures (21). Therefore, investigating the pathophysiology and pharmacological interventions of S-IRA is of great significance to foster the development of new avenues to prevent SUDEP in patients.

Genistein (4',5,7-trihydroxyisoflavone) is a natural isoflavone that is found in a variety of dietary vegetables such as soybeans and fava beans (22). As a phytoestrogen, genistein displays a myriad of biological activities and is used for the treatment of many diseases, e.g., post-menopausal syndrome, cancer, cardiovascular disease and diabetes (23-25). Genistein inhibits the reuptake of norepinephrine in human neuroblastoma cells (26); i.e., it is a norepinephrine reuptake inhibitor (NRI). It was reported that genistein enhances serotonin (5-HT) function (27-30) and exerts anticonvulsant effect in rodents $(27,28)$. Previous studies demonstrated that augmenting the function of certain monoamines (5-HT or norepinephrine) suppresses SIRA in DBA/1 mice $(18,31-35)$. Therefore, we hypothesized that genistein could alleviate S-IRA in DBA/1 mice. The aim of this study is to examine the effect of genistein on the incidence of S-IRA and explore the monoaminergic mechanism underlying genistein's action on S-IRA.

\section{MATERIALS AND METHODS}

\section{Animals}

DBA/1 mice were originally obtained from Envigo (Indianapolis, IN, USA) and were housed and bred in the animal facility under a temperature- and humidity-controlled environment (12h light/dark cycle) at Massachusetts General Hospital. All animals were provided with rodent food and water ad libitum. DBA/1 mice were primed by daily exposure to acoustic stimulation for 3-4 days from post-natal day 26. Once a DBA/1 mouse displayed S-IRA after generalized audiogenic seizures and was resuscitated (see below), it became susceptible to S-IRA in subsequent tests. Primed DBA/ 1 mice of both sexes at $\sim 2$ months of age were used in the experiments. The animal protocol (\# 2012N000024) was approved by the Massachusetts General Hospital Institutional Animal Care and Use Committee. Every effort was made to reduce the stress of the animals and minimize the number of the animals used in experiments.

\section{Drugs}

Genistein (G6649), prazosin hydrochloride (P7791), yohimbine hydrochloride (Y3125), and ondansetron hydrochloride dihydrate (O3639) were purchased from Millipore Sigma (St. Louis, MO, USA), and ketanserin tartrate (0908) was obtained from R\&D Systems (Minneapolis, MN, USA). Genistein was

Abbreviations: 5-HT, Serotonin; 5-HTP, 5-Hydroxytryptophan; i.p., Intraperitoneal(ly); NRI, Norepinephrine reuptake inhibitor; S-IRA, Seizureinduced respiratory arrest; SSRI, Selective serotonin reuptake inhibitor; SUDEP, Sudden unexpected death in epilepsy. dissolved in 60\% dimethyl sulfoxide (DMSO) and 40\% saline $(0.9 \% \mathrm{NaCl})$, and all other agents were dissolved in saline.

\section{Effects on S-IRA of Genistein and Genistein in Combination With an Adrenoceptor Antagonist or a 5-HT Receptor Antagonist}

As previously described (36), a primed DBA/1 mouse was placed in a cylindrical plexiglass chamber, and audiogenic seizures were evoked by acoustic stimulation using an electric bell (96 dB SPL) in a sound-isolated room. The acoustic stimulus was presented for up to $1 \mathrm{~min}$ or until the mouse exhibited wild running and generalized tonic-clonic seizures followed by S-IRA. Once S-IRA occurred, the mouse was resuscitated using a rodent respirator (Harvard Apparatus 680, Holliston, MA, USA) (7).

S-IRA susceptibility was confirmed in all primed DBA/1 mice $24 \mathrm{~h}$ prior to the experiment. The effect of genistein or vehicle on the incidence of S-IRA and seizure behaviors was tested by intraperitoneal (i.p.) injection of various dosages of genistein or the vehicle $(10 \mathrm{ml} / \mathrm{kg}) 2 \mathrm{~h}$ prior to acoustic stimulation. To assess whether the noradrenergic or 5-HT signaling was involved in the action of genistein, an adrenoceptor antagonist or a 5-HT receptor antagonist was administered $30 \mathrm{~min}$ prior to genistein injection, and acoustic stimulation was applied $2 \mathrm{~h}$ after genistein injection. The effect of the antagonist alone on S-IRA was examined by i.p. administration of the drug $2.5 \mathrm{~h}$ prior to acoustic stimulation.

Audiogenic seizures and S-IRA were digitally recorded using a video camera for offline analysis. For those mice in which SIRA was blocked during the test, recovery of the susceptibility to S-IRA was examined at 24 -h intervals after the test until it returned.

\section{Statistical Analysis}

Statistical analysis was performed using Prism 5.0d software (GraphPad Software Inc., La Jolla, CA, USA). S-IRA incidence between the treatment and vehicle group or between the treatment groups was compared using Chi-square test (twotailed). Statistical significance was considered if $p<0.05$.

\section{RESULTS}

\section{Genistein Reduces S-IRA in DBA/1 Mice}

The incidence of S-IRA in DBA/1 mice was significantly reduced $2 \mathrm{~h}$ after i.p. administration of genistein at $1 \mathrm{mg} / \mathrm{kg}(12.5 \%, n=$ 8; $p<0.01), 10 \mathrm{mg} / \mathrm{kg}(25 \%, n=8 ; p<0.05), 30 \mathrm{mg} / \mathrm{kg}(23.1 \%$, $n=13 ; p<0.01), 60 \mathrm{mg} / \mathrm{kg}(41.2 \%, n=17 ; p<0.05)$, and 90 $\mathrm{mg} / \mathrm{kg}(22.2 \%, n=9 ; p<0.01)$ as compared with that in the vehicle control $(87.5 \%, n=8)$. However, compared with that in the vehicle control, the incidence of S-IRA was not significantly suppressed by genistein at $0.2 \mathrm{mg} / \mathrm{kg}(50 \%, n=8)$ (Figure 1).

Among those DBA/1 mice whose S-IRA was blocked by genistein, genistein at $1 \mathrm{mg} / \mathrm{kg}$ inhibited S-IRA without interfering with any component of audiogenic seizures in $100 \%$ of mice, suggesting that genistein specifically blocks S-IRA in these mice. Genistein specifically blocked S-IRA in $100 \%$ of mice at 10 $\mathrm{mg} / \mathrm{kg}, 90 \%$ at $30 \mathrm{mg} / \mathrm{kg}, 80 \%$ at $60 \mathrm{mg} / \mathrm{kg}$ and $42.9 \%$ at $90 \mathrm{mg} / \mathrm{kg}$. 


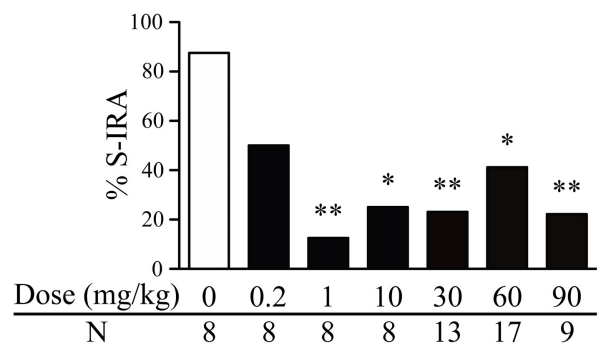

FIGURE 1 | Genistein reduces the incidence of S-IRA in DBA/1 mice. Compared with vehicle control (dose zero), systemic administration of genistein at $1-90 \mathrm{mg} / \mathrm{kg}$ significantly decreased the incidence of S-IRA in DBA/1 mice. S-IRA incidence was not significantly altered by genistein at 0.2 $\mathrm{mg} / \mathrm{kg}$ compared with vehicle control. ${ }^{\star} p<0.05$; ${ }^{* *} p<0.01$ : Significantly different from the vehicle control (dose zero).

At relatively higher dosages, genistein also produced a considerable anticonvulsant effect. Genistein blocked tonicclonic seizures in $7.7 \%$ of mice at $30 \mathrm{mg} / \mathrm{kg}, 11.8 \%$ of mice at $60 \mathrm{mg} / \mathrm{kg}$ and $44.4 \%$ of mice at $90 \mathrm{mg} / \mathrm{kg}$. At these dosages of genistein, wild running seizures were still observed in the majority of mice; $92.3 \%$ at $30 \mathrm{mg} / \mathrm{kg}, 88.2 \%$ at $60 \mathrm{mg} / \mathrm{kg}$ and $88.9 \%$ at $90 \mathrm{mg} / \mathrm{kg}$.

\section{The S-IRA-Suppressing Effect of Genistein Is Reversed by an $\alpha 2$ Adrenoceptor Antagonist}

The incidence of S-IRA tested $2.5 \mathrm{~h}$ after administration of the $\alpha 1$ adrenoceptor antagonist prazosin alone $(1 \mathrm{mg} / \mathrm{kg})(87.5 \%, n=$ 8 ) or the $\alpha 2$ adrenoceptor antagonist yohimbine alone ( $5 \mathrm{mg} / \mathrm{kg}$ ) $(100 \%, n=8)$ was not significantly different from tests $24 \mathrm{~h}$ prior to the experiment (100\%). Compared with the incidence of S-IRA in the presence of $1 \mathrm{mg} / \mathrm{kg}$ genistein alone $(27.3 \%$, $n=22$ ), administration of yohimbine $(5 \mathrm{mg} / \mathrm{kg}) 30 \mathrm{~min}$ prior to genistein injection $(1 \mathrm{mg} / \mathrm{kg})$ significantly increased S-IRA incidence to $72.7 \%(n=11 ; p<0.05)$. Although administration of prazosin (1 mg/kg) $30 \mathrm{~min}$ before genistein injection (1 $\mathrm{mg} / \mathrm{kg}$ ) also enhanced S-IRA incidence, the enhancement was not significantly different from that evoked by genistein alone (1 $\mathrm{mg} / \mathrm{kg})(p=0.135)$ (Figure 2A).

Compared with the incidence of S-IRA tested $24 \mathrm{~h}$ prior to the experiment $(100 \%)$, administration of the $5-\mathrm{HT}_{2 \mathrm{~A}}$ receptor antagonist ketanserin alone $(0.5 \mathrm{mg} / \mathrm{kg})(75 \%, n=8)$ or the 5 $\mathrm{HT}_{3}$ receptor antagonist ondansetron alone $(2 \mathrm{mg} / \mathrm{kg})(87.5 \%$, $n=8) 2.5 \mathrm{~h}$ prior to acoustic stimulation did not significantly alter S-IRA incidence. Administration of ketanserin $(0.5 \mathrm{mg} / \mathrm{kg})$ or ondansetron $(2 \mathrm{mg} / \mathrm{kg}) 30 \mathrm{~min}$ ahead of genistein injection (1 $\mathrm{mg} / \mathrm{kg}$ ) did not significantly change S-IRA incidence as compared with that evoked by genistein alone (1 mg/kg) (Figure 2B).

\section{DISCUSSION}

We report in this study that systemic administration of genistein, a compound found in many dietary vegetables and a dietary supplement widely available over the counter, lowers the
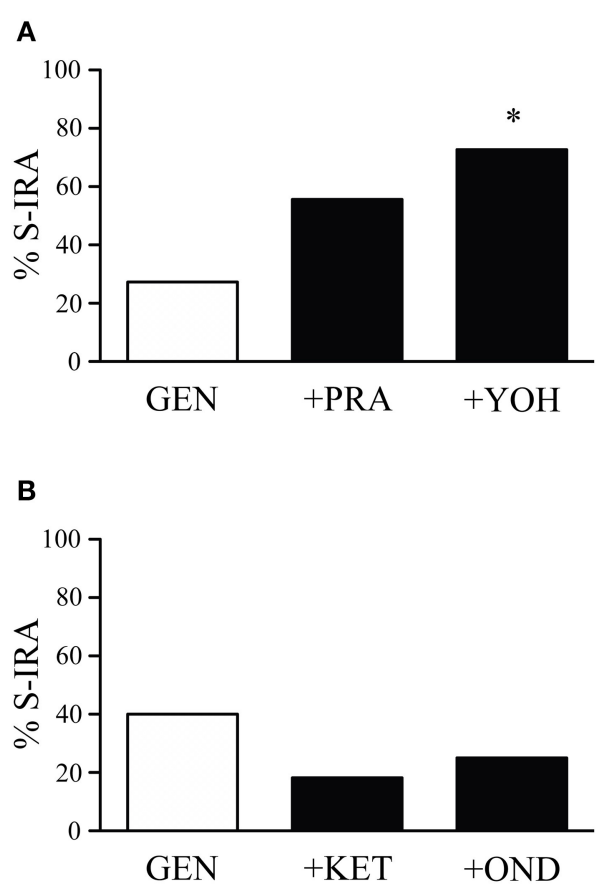

FIGURE 2 | The suppressing effect of genistein on S-IRA in DBA/1 mice is prevented by an $\alpha 2$ adrenoceptor antagonist but not by an $\alpha 1$ adrenoceptor antagonist as well as a $5-\mathrm{HT}_{2 \mathrm{~A}}$ or $5-\mathrm{HT}_{3}$ receptor antagonist. (A) Compared with the incidence of S-IRA evoked by genistein alone $(1 \mathrm{mg} / \mathrm{kg})$, administration of the $\alpha 2$ adrenoceptor antagonist yohimbine $(5 \mathrm{mg} / \mathrm{kg}) 30 \mathrm{~min}$ prior to genistein injection $(1 \mathrm{mg} / \mathrm{kg}$ ) significantly elevated S-IRA incidence. Administration of the $\alpha 1$ adrenoceptor antagonist prazosin $(1 \mathrm{mg} / \mathrm{kg}) 30 \mathrm{~min}$ before genistein injection $(1 \mathrm{mg} / \mathrm{kg}$ ) did not significantly change S-IRA incidence compared with that evoked by genistein alone (1 mg/kg). (B) Compared with the incidence of S-IRA evoked by genistein alone $(1 \mathrm{mg} / \mathrm{kg})$, administration of the $5-\mathrm{HT}_{2 \mathrm{~A}}$ receptor antagonist ketanserin $(0.5 \mathrm{mg} / \mathrm{kg})$ or the $5-\mathrm{HT}_{3}$ receptor antagonist ondansetron $(2 \mathrm{mg} / \mathrm{kg}) 30 \mathrm{~min}$ prior to genistein injection $\left(1 \mathrm{mg} / \mathrm{kg}\right.$ ) did not significantly alter S-IRA incidence. ${ }^{*} p<0.05$ : Significantly different from the effect on S-IRA evoked by genistein alone.

incidence of S-IRA and specifically blocks S-IRA in DBA/1 mice. The S-IRA-suppressing effect of genistein is reversed by an $\alpha 2$ adrenoceptor antagonist but not by an $\alpha 1$ antagonist or 5-HT receptor antagonists, suggesting that genistein reduces S-IRA incidence by stimulating $\alpha 2$ adrenoceptors.

\section{Genistein as a Dietary Supplement Reduces S-IRA Incidence and Specifically Blocks S-IRA in DBA/1 Mice}

It is urgent to develop effective strategies to prevent SUDEP (1). One useful approach to impeding SUDEP is the pharmacological treatment to minimize the risk of generalized tonic-clonic seizures, a seizure type that triggers the majority of witnessed $\operatorname{SUDEP}(37,38)$. Although various antiseizure drugs are available for control of seizures, approximately one-third of patients are refractory to the treatment with current medications (39). Thus, it is very important to develop new avenues for treatment of epilepsy and SUDEP, as the SUDEP rate is high for patients with refractory epilepsy (3). 
It was reported that 5-hydroxytryptophan (5-HTP), a precursor for 5-HT synthesis, suppresses S-IRA in DBA/1 mice (18). 5-HTP is extracted from the seeds of a plant known as Griffonia simplicifolia and is widely used as an over-the-counter dietary supplement to relieve the symptoms of 5-HT-related disorders (40). In the current study, we observed that genistein reduces the incidence of S-IRA in DBA/1 mice. Also as an overthe-counter dietary supplement, genistein is advantageous to 5HTP in its easy availability. Genistein is present in the fruit of a plant named Sophora japonica Leguminosae (41). Interestingly, it is abundantly found in a variety of dietary vegetables, including soybeans, lupin and fava beans, which are widely consumed by people around the world $(42,43)$.

It appears that genistein effect on S-IRA is not clearly dosedependent. The reasons underlying this lack of dose-response for genistein action are unknown. However, it was reported that selective serotonin reuptake inhibitors (SSRIs) are not dosedependent when used as antidepressants $(44,45)$, which may be due to complicated factors that include autoreceptor regulation $(46,47)$. As genistein is an NRI, similar factors may contribute to the current observation that genistein reduces S-IRA in a relatively dose-independent manner.

Genistein can selectively block S-IRA without interrupting any component of audiogenic seizures, especially at relatively lower dosages. This finding is reminiscent of the effects of 5HT-enhancing agents such as SSRIs and NRIs on S-IRA. It was reported that several SSRIs including fluoxetine and sertraline $(31,36,48,49)$ and 5-HTP (18) can specifically inhibit S-IRA. The NRI atomoxetine can also selectively block S-IRA $(33,34)$. The selective inhibition of S-IRA by genistein indicates that it may achieve this effect via stimulating noradrenergic and/or 5-HT neurotransmission.

\section{Noradrenergic but Not 5-HT Neurotransmission Is Involved in the Inhibition of S-IRA by Genistein}

How does genistein work to suppress S-IRA in DBA/1 mice? Our study demonstrated that the inhibitory effect of genistein on S-IRA was prevented by the $\alpha 2$ adrenoceptor antagonist yohimbine but was not significantly altered by the $\alpha 1$ adrenoceptor antagonist prazosin. These findings indicate that genistein reduces S-IRA by enhancing noradrenergic neurotransmission and activating $\alpha 2$ adrenoceptors. Consistent with this, it was reported that genistein inhibits the reuptake of norepinephrine by reducing the activity of norepinephrine transporters in human neuroblastoma cells (26), indicating that genistein is an NRI. Interestingly, our recent data show that the traditional NRI atomoxetine reduces S-IRA via activation of $\alpha 2$ adrenoceptors (50). $\alpha 2$ adrenoceptors are found both pre-synaptically and post-synaptically in the CNS (51). Genistein alleviates S-IRA in DBA/1 mice likely through the activation of post-synaptic $\alpha 2$ adrenoceptors, as pre-synaptic $\alpha 2$ adrenoceptors are autoreceptors, and activation of these receptors would inhibit norepinephrine release (51).
In the present study, we observed that the S-IRA-suppressing effect of genistein cannot be reversed by antagonists of 5$\mathrm{HT}_{2 \mathrm{~A}}$ and $5-\mathrm{HT}_{3}$ receptors, which were previously shown to be involved in S-IRA in provoked seizure models $(17,32,35)$. This observation suggests it is unlikely that 5-HT neurotransmission contributes to genistein inhibition of S-IRA in DBA/1 mice. Genistein was reported to augment 5-HT neurotransmission (27-30) and engender anticonvulsant effects in rodents through the 5 -HT system $(27,28)$. In line with this, we found that genistein at relatively high dosages produces anticonvulsant effects in DBA/1 mice. Further studies are needed to explore if 5HT signaling is involved in the anticonvulsant action of genistein in this animal model.

In the current study, we only focused on the pharmacologic effect of genistein on S-IRA by systemic administration of this compound. More studies are needed in the future to investigate the detailed action of genistein such as the molecular mechanism underlying genistein regulation of S-IRA and the nuclei where genistein exerts its effect in the brain.

\section{CONCLUSIONS}

In summary, our data demonstrate that genistein, a natural diet supplement, reduces the incidence of S-IRA in DBA/1 mice. It can selectively block S-IRA without interrupting any component of seizures at relatively lower dosages and produces anticonvulsant effects at relatively higher dosages. The suppressing effect of genistein on S-IRA is dependent on the activation of $\alpha 2$ adrenoceptors. These data suggest that genistein is potentially useful to prevent SUDEP in at-risk patients.

\section{DATA AVAILABILITY STATEMENT}

The raw data supporting the conclusions of this article will be made available by the authors, without undue reservation.

\section{ETHICS STATEMENT}

The animal study was reviewed and approved by Massachusetts General Hospital Institutional Animal Care and Use Committee (IACUC).

\section{AUTHOR CONTRIBUTIONS}

JG carried out experiments, performed data analysis, and drafted the manuscript. DM performed experiments. H-JF conceptualized the idea and wrote and edited the manuscript. All authors contributed to the article and approved the submitted version.

\section{FUNDING}

This work was supported by NIH R01 NS112319 and the fund from the Massachusetts General Hospital Department of Anesthesia, Critical 
Care and Pain Medicine to H-JF. JG was a recipient of the graduate fellowship from China Scholarship Council.

\section{REFERENCES}

1. Thurman DJ, Hesdorffer DC, French JA. Sudden unexpected death in epilepsy: assessing the public health burden. Epilepsia. (2014) 55:1479-85. doi: 10.1111/epi.12666

2. Tomson T, Surges R, Delamont R, Haywood S, Hesdorffer DC. Who to target in sudden unexpected death in epilepsy prevention and how? Risk factors, biomarkers, and intervention study designs. Epilepsia. (2016) 57 (Suppl. 1):4-16. doi: 10.1111/epi.13234

3. Tomson T, Nashef L, Ryvlin P. Sudden unexpected death in epilepsy: current knowledge and future directions. Lancet Neurol. (2008) 7:1021-31. doi: 10.1016/S1474-4422(08)70202-3

4. Kalume F, Westenbroek RE, Cheah CS, Yu FH, Oakley JC, Scheuer T, et al. Sudden unexpected death in a mouse model of Dravet syndrome. J Clin Investig. (2013) 123:1798-808. doi: 10.1172/JCI66220

5. Aiba I, Noebels JL. Spreading depolarization in the brainstem mediates sudden cardiorespiratory arrest in mouse SUDEP models. Sci Transl Med. (2015) 7:282ra46. doi: 10.1126/scitranslmed.aaa4050

6. Nakase K, Kollmar R, Lazar J, Arjomandi H, Sundaram K, Silverman J, et al. Laryngospasm, central and obstructive apnea during seizures: defining pathophysiology for sudden death in a rat model. Epilepsy Res. (2016) 128:126-39. doi: 10.1016/j.eplepsyres.2016.08.004

7. Feng HJ, Faingold CL. Abnormalities of serotonergic neurotransmission in animal models of SUDEP. Epilepsy Behav. (2017) 71 (Pt B):174-80. doi: 10.1016/j.yebeh.2015.06.008

8. Schilling WP, McGrath MK, Yang T, Glazebrook PA, Faingold CL, Kunze DL. Simultaneous cardiac and respiratory inhibition during seizure precedes death in the DBA/1 audiogenic mouse model of SUDEP. PLOS ONE. (2019) 14:e0223468. doi: 10.1371/journal.pone. 0223468

9. Budde RB, Pederson DJ, Biggs EN, Jefferys JGR, Irazoqui PP. Mechanisms and prevention of acid reflux induced laryngospasm in seizing rats. Epilepsy Behav. (2020) 111:107188. doi: 10.1016/j.yebeh.2020.107188

10. Langan Y, Nashef L, Sander JW. Sudden unexpected death in epilepsy: a series of witnessed deaths. J Neurol Neurosurg Psychiatry. (2000) 68:211-3. doi: $10.1136 /$ jnnp.68.2.211

11. So EL, Sam MC, Lagerlund TL. Postictal central apnea as a cause of SUDEP: evidence from near-SUDEP incident. Epilepsia. (2000) 41:1494-7. doi: 10.1111/j.1528-1157.2000.tb00128.x

12. Bateman LM, Li CS, Seyal M. Ictal hypoxemia in localization-related epilepsy: analysis of incidence, severity and risk factors. Brain J Neurol. (2008) 131 (Pt 12):3239-45. doi: 10.1093/brain/awn277

13. Blum AS. Respiratory physiology of seizures. J Clin Neurophysiol. (2009) 26:309-15. doi: 10.1097/WNP.0b013e3181b7f14d

14. Pezzella M, Striano P, Ciampa C, Errichiello L, Penza P, Striano S. Severe pulmonary congestion in a near miss at the first seizure: further evidence for respiratory dysfunction in sudden unexpected death in epilepsy. Epilepsy Behav. (2009) 14:701-2. doi: 10.1016/j.yebeh.2009.02.012

15. Faingold CL, Randall M, Tupal S. DBA/1 mice exhibit chronic susceptibility to audiogenic seizures followed by sudden death associated with respiratory arrest. Epilepsy Behav. (2010) 17:436-40. doi: 10.1016/j.yebeh.2010.02.007

16. Ryvlin P, Nashef L, Lhatoo SD, Bateman LM, Bird J, Bleasel A, et al. Incidence and mechanisms of cardiorespiratory arrests in epilepsy monitoring units (MORTEMUS): a retrospective study. Lancet Neurol. (2013) 12:966-77. doi: 10.1016/S1474-4422(13)70214-X

17. Buchanan GF, Murray NM, Hajek MA, Richerson GB. Serotonin neurones have anti-convulsant effects and reduce seizure-induced mortality. J Physiol. (2014) 592 (Pt 19):4395-410. doi: 10.1113/jphysiol.2014.277574

18. Zhang H, Zhao H, Yang X, Xue Q, Cotten JF, Feng HJ. 5-Hydroxytryptophan, a precursor for serotonin synthesis, reduces seizure-induced respiratory arrest. Epilepsia. (2016) 57:1228-35. doi: 10.1111/epi.13430

\section{ACKNOWLEDGMENTS}

We thank Dr. Siyuan Yuan for useful discussion.
19. Kim Y, Bravo E, Thirnbeck CK, Smith-Mellecker LA, Kim SH, Gehlbach BK, et al. Severe peri-ictal respiratory dysfunction is common in Dravet syndrome. J Clin Investig. (2018) 128:1141-53. doi: 10.1172/JCI94999

20. Dhaibar H, Gautier NM, Chernyshev OY, Dominic P, Glasscock E. Cardiorespiratory profiling reveals primary breathing dysfunction in Kcna1null mice: implications for sudden unexpected death in epilepsy. Neurobiol Dis. (2019) 127:502-11. doi: 10.1016/j.nbd.2019.04.006

21. Bauman K, Devinsky O. Seizure clusters: morbidity and mortality. Front Neurol. (2021) 12:636045. doi: 10.3389/fneur.2021.636045

22. Dixon RA, Ferreira D. Genistein. Phytochemistry. (2002) 60:205-11. doi: 10.1016/S0031-9422(02)00116-4

23. Mukund V, Mukund D, Sharma V, Mannarapu M, Alam A. Genistein: its role in metabolic diseases and cancer. Crit Rev Oncol Hematol. (2017) 119:13-22. doi: 10.1016/j.critrevonc.2017.09.004

24. Thangavel P, Puga-Olguin A, Rodriguez-Landa JF, Zepeda RC. Genistein as potential therapeutic candidate for menopausal symptoms and other related diseases. Molecules. (2019) 24:3892. doi: 10.3390/molecules 24213892

25. Braxas H, Rafraf M, Karimi Hasanabad S, Asghari Jafarabadi M. Effectiveness of genistein supplementation on metabolic factors and antioxidant status in postmenopausal women with type 2 diabetes mellitus. Can J Diabetes. (2019) 43:490-7. doi: 10.1016/j.jcjd.2019.04.007

26. Apparsundaram S, Sung U, Price RD, Blakely RD. Trafficking-dependent and -independent pathways of neurotransmitter transporter regulation differentially involving p38 mitogen-activated protein kinase revealed in studies of insulin modulation of norepinephrine transport in SK-N-SH cells. $J$ Pharmacol Exp Ther. (2001) 299:666-77.

27. Amiri Gheshlaghi S, Mohammad Jafari R, Algazo M, Rahimi N, Alshaib H, Dehpour AR. Genistein modulation of seizure: involvement of estrogen and serotonin receptors. J Nat Med. (2017) 71:537-44. doi: 10.1007/s11418-017-1088-3

28. Hu P, Ma L, Wang YG, Ye F, Wang C, Zhou WH, et al. Genistein, a dietary soy isoflavone, exerts antidepressant-like effects in mice: involvement of serotonergic system. Neurochem Int. (2017) 108:426-35. doi: 10.1016/j.neuint.2017.06.002

29. Wu ZM, Ni GL, Shao AM, Cui R. Genistein alleviates anxiety-like behaviors in post-traumatic stress disorder model through enhancing serotonergic transmission in the amygdala. Psychiatry Res. (2017) 255:287-91. doi: 10.1016/j.psychres.2017.05.051

30. Lee B, Choi GM, Shim I, Lee H. Genistein prevents single prolonged stressinduced cognitive impairment in a post-traumatic stress disorder rat model via activation of the serotonergic system. J Med Food. (2020) 23:476-84. doi: 10.1089/jmf.2019.4519

31. Faingold CL, Tupal S, Randall M. Prevention of seizure-induced sudden death in a chronic SUDEP model by semichronic administration of a selective serotonin reuptake inhibitor. Epilepsy Behav. (2011) 22:186-90. doi: 10.1016/j.yebeh.2011.06.015

32. Faingold CL, Randall M, Zeng C, Peng S, Long X, Feng HJ. Serotonergic agents act on 5 -HT3 receptors in the brain to block seizure-induced respiratory arrest in the DBA/1 mouse model of SUDEP. Epilepsy Behav. (2016) 64 (Pt A):166-70. doi: 10.1016/j.yebeh.2016.09.034

33. Zhang H, Zhao H, Feng HJ. Atomoxetine, a norepinephrine reuptake inhibitor, reduces seizure-induced respiratory arrest. Epilepsy Behav. (2017) 73:6-9. doi: 10.1016/j.yebeh.2017.04.046

34. Zhao H, Cotten JF, Long X, Feng HJ. The effect of atomoxetine, a selective norepinephrine reuptake inhibitor, on respiratory arrest and cardiorespiratory function in the DBA/1 mouse model of SUDEP. Epilepsy Res. (2017) 137:13944. doi: 10.1016/j.eplepsyres.2017.08.005

35. Zhang H, Zhao H, Zeng C, Van Dort C, Faingold CL, Taylor NE, et al. Optogenetic activation of 5-HT neurons in the dorsal raphe suppresses seizure-induced respiratory arrest and produces anticonvulsant effect in 
the DBA/1 mouse SUDEP model. Neurobiol Dis. (2018) 110:47-58. doi: 10.1016/j.nbd.2017.11.003

36. Zeng C, Long X, Cotten JF, Forman SA, Solt K, Faingold CL, et al. Fluoxetine prevents respiratory arrest without enhancing ventilation in DBA/1 mice. Epilepsy Behav. (2015) 45:1-7. doi: 10.1016/j.yebeh.2015.02.013

37. Ryvlin P, Nashef L, Tomson T. Prevention of sudden unexpected death in epilepsy: a realistic goal? Epilepsia. (2013) 54 (Suppl. 2):23-8. doi: 10.1111/epi.12180

38. Sveinsson O, Andersson T, Mattsson P, Carlsson S, Tomson T. Pharmacologic treatment and SUDEP risk: a nationwide, population-based, case-control study. Neurology. (2020) 95:e2509-18. doi: 10.1212/WNL.0000000000010874

39. Galanopoulou AS, Buckmaster PS, Staley KJ, Moshe SL, Perucca E, Engel J, et al. Identification of new epilepsy treatments: issues in preclinical methodology. Epilepsia. (2012) 53:571-82. doi: 10.1111/ j.1528-1167.2011.03391.x

40. Vigliante I, Mannino G, Maffei ME. Chemical characterization and DNA fingerprinting of Griffonia simplicifolia Baill. Molecules. (2019) 24:1032. doi: 10.3390/molecules 24061032

41. Wang ZL, Sun JY, Wang DN, Xie YH, Wang SW, Zhao WM. Pharmacological studies of the large-scaled purified genistein from Huaijiao (Sophora japonicaLeguminosae) on anti-osteoporosis. Phytomedicine. (2006) 13:718-23. doi: 10.1016/j.phymed.2005.09.005

42. Kaufman PB, Duke JA, Brielmann H, Boik J, Hoyt JE. A comparative survey of leguminous plants as sources of the isoflavones, genistein and daidzein: implications for human nutrition and health. J Altern Complement Med. (1997) 3:7-12. doi: 10.1089/acm.1997.3.7

43. Marini H, Polito F, Adamo EB, Bitto A, Squadrito F, Benvenga S. Update on genistein and thyroid: an overall message of safety. Front Endocrinol. (2012) 3:94. doi: 10.3389/fendo.2012.00094

44. Braun C, Adams A, Rink L, Bschor T, Kuhr K, Baethge C. In search of a dose-response relationship in SSRIs-a systematic review, meta-analysis, and network meta-analysis. Acta Psychiatr Scand. (2020) 142:430-42. doi: 10.1111/ acps. 13235

45. Furukawa TA, Cipriani A, Cowen PJ, Leucht S, Egger M, Salanti G. Optimal dose of selective serotonin reuptake inhibitors, venlafaxine, and mirtazapine in major depression: a systematic review and dose-response meta-analysis. Lancet Psychiatry. (2019) 6:601-9. doi: 10.1016/S2215-0366(19)30217-2
46. Terao T. Dampening antidepressant effects via 5-HT1A auto-receptors. Acta Psychiatr Scand. (2021) 143:94-5. doi: 10.1111/acps.13244

47. Ruhe HG, Booij J, v Weert HC, Reitsma JB, Franssen EJ, Michel MC, et al. Evidence why paroxetine dose escalation is not effective in major depressive disorder: a randomized controlled trial with assessment of serotonin transporter occupancy. Neuropsychopharmacology. (2009) 34:9991010. doi: $10.1038 /$ npp. 2008.148

48. Tupal S, Faingold CL. Evidence supporting a role of serotonin in modulation of sudden death induced by seizures in DBA/2 mice. Epilepsia. (2006) 47:21-6. doi: $10.1111 / j .1528-1167.2006 .00365 . x$

49. Faingold CL, Randall M. Effects of age, sex, and sertraline administration on seizure-induced respiratory arrest in the DBA/1 mouse model of sudden unexpected death in epilepsy (SUDEP). Epilepsy Behav. (2013) 28:78-82. doi: 10.1016/j.yebeh.2013.04.003

50. Zhang R, Tan Z, Niu J, Feng HJ. Adrenergic alpha2 receptors are implicated in seizure-induced respiratory arrest in DBA/1 mice. Life Sci. (2021) 284:119912. doi: 10.1016/j.lfs.2021.119912

51. Hussain LS, Maani CV. Physiology, Noradrenergic Synapse. Treasure Island, FL: StatPearls (2019).

Conflict of Interest: The authors declare that the research was conducted in the absence of any commercial or financial relationships that could be construed as a potential conflict of interest.

Publisher's Note: All claims expressed in this article are solely those of the authors and do not necessarily represent those of their affiliated organizations, or those of the publisher, the editors and the reviewers. Any product that may be evaluated in this article, or claim that may be made by its manufacturer, is not guaranteed or endorsed by the publisher.

Copyright $\odot 2021$ Guo, Min and Feng. This is an open-access article distributed under the terms of the Creative Commons Attribution License (CC BY). The use, distribution or reproduction in other forums is permitted, provided the original author(s) and the copyright owner(s) are credited and that the original publication in this journal is cited, in accordance with accepted academic practice. No use, distribution or reproduction is permitted which does not comply with these terms. 